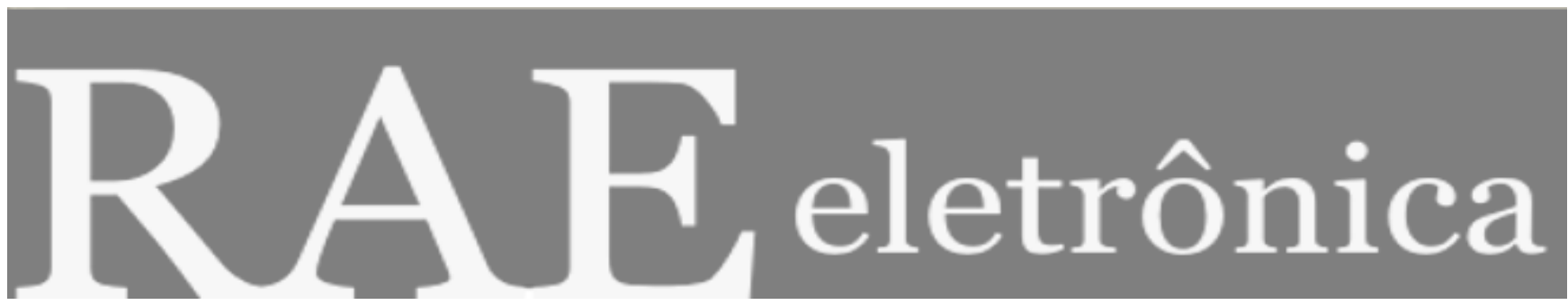

\title{
AVALIAÇÃO DE DESEMPENHO NA ÁREA PÚBLICA: PERSPECTIVAS E PROPOSTAS FRENTE A DOIS CASOS PRÁTICOS
}

Por:

\section{Gabriela Spanghero Lotta}

RAE-eletrônica, Volume 1, Número 2, jul-dez/2002.

CCopyright, 2002, RAE-eletrônica. Todos os direitos, inclusive de tradução, são reservados. É permitido citar parte de artigos sem autorização prévia desde que seja identificada a fonte. A reprodução total de artigos é proibida. Os artigos só devem ser usados para uso pessoal e nãocomercial. Em caso de dúvidas, consulte a redação: redacao@rae.com.br.

A RAE-eletrônica é a revista on-line da FGV-EAESP, totalmente aberta e criada com o objetivo de agilizar a veiculação de trabalhos inéditos. Lançada em janeiro de 2002, com perfil acadêmico, é dedicada a professores, pesquisadores e estudantes. Para mais informações consulte o site www.rae.com.br/eletronica.

RAE-eletrônica

ISSN 1676-5648

(C)2002 Editora: Fundação Getulio Vargas - Escola de Administração

de Empresas de São Paulo.

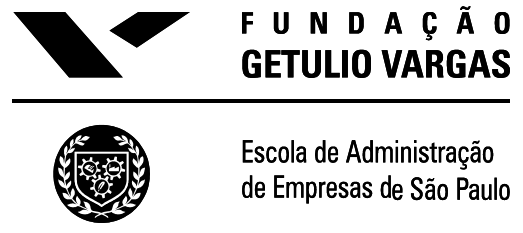




\title{
AVALIAÇÃO DE DESEMPENHO NA ÁREA PÚBLICA: PERSPECTIVAS E PROPOSTAS FRENTE A DOIS CASOS PRÁTICOS
}

\section{Gabriela Spanghero Lotta}

Graduanda em Administração Pública pela FGV- EAESP e Assistente de Pesquisa da Oficina Municipal pela Fundação Konrad Adenauer

E-mail: gabriela@oficinamunicipal.com.br

\section{RESUMO}

O artigo trata de uma pesquisa comparativa feita entre a avaliação de desempenho utilizada em duas prefeituras, São Paulo - Brasil, e Sonthofen - Alemanha. Ressaltam-se as particularidades de cada instrumento, adequado ao contexto e legislação locais. Analisam-se os pontos comuns, principalmente no que se trata de suas deficiências. Analisados as relatividades de ambas, faz-se uma comparação dos problemas comuns bem como seus motivos. A seguir, propõem-se algumas mudanças necessárias a fim de que a avaliação possa ser utilizada como instrumento de planejamento estratégico e modernização da administração pública. Ressalta-se, ainda, ao final, como realidades tão diferentes podem apresentar deficiências comuns.

\begin{abstract}
This article is the result of a comparative research made between the performance assessments used in two differents majorities, São Paulo - Brazil and Sonthofen - Germany. The particularities of each instrument, connected to the local contests and the legislation are investigated. The common points are analyzed, mainly their deficiencies. After analyzing their relativities, the problems and their motives are compared. Then, some necessary changes are proposed, in the way to make the performance assessment an instrument for a strategic planing and for the modernization of the public management. At the end is evidenced how two different realities can have the same deficiencies.
\end{abstract}

\section{PALAVRAS-CHAVE}

Avaliação de desempenho, administração pública, São Paulo, Alemanha, prefeituras.

\section{KEY WORDS}

Performance assessments, public management, São Paulo, Germany, mayority. 


\section{INTRODUÇÃO}

Em um ambiente extremamente competitivo, marcado pela globalização e por fatores dinâmicos, a área de recursos humanos surge como setor estratégico para o desenvolvimento das organizações. Levandose em consideração o ambiente público - ainda tido como retrógrado perante os avanços mundiais observa-se que a área de Recursos Humanos é fator primordial para adequar a realidade pública aos novos paradigmas administrativos que primam pela eficiência, baixos custos, rapidez e bons serviços.

O presente trabalho visa a analisar os aspectos relacionados aos recursos humanos nas organizações de administração pública, no que tange especificamente a questão da Avaliação de Desempenho, considerando seus objetivos, parâmetros e importância na realidade dessas organizações. Para identificar realidades e problemas associados à atual utilização da Avaliação de Desempenho na Administração Pública, serão utilizados dois exemplos práticos, baseados em experiências realizadas nas prefeituras de São Paulo, Brasil e Sonthofen, Alemanha. Embora tais experiências pareçam ser antagônicas, pontos comuns serão traçados.

\section{AVALIAÇÃO DE DESEMPENHO FRENTE À ADMINISTRAÇÃO DE RECURSOS HUMANOS}

Se levarmos em consideração a participação da Avaliação de Desempenho no ambiente organizacional, estaremos nos deparando com a nova função pela qual a área de Recursos Humanos é responsável: a função de planejamento estratégico da organização. Assim, observamos que a tradicional responsabilidade dessa área, no sentido de controlar, registrar e fazer o pagamento, é deixada de lado, em prol de políticas desenvolvimentistas para os profissionais das organizações, englobando funções como planejamento, organização, direção, controle, treinamento, manutenção, utilização, motivação e desenvolvimento, entre outras.

A avaliação de desempenho é um mecanismo que busca conhecer e medir o desempenho dos indivíduos na organização, estabelecendo uma comparação entre o desempenho esperado e o apresentado por esses indivíduos.

Andreassi (1994) dividiu os objetivos da avaliação em 5 áreas principais: treinamento/desenvolvimento, aumentos salariais e promoção, comunicação, planejamento de recursos humanos e aspectos legais.

De acordo com a função de treinamento e desenvolvimento, a avaliação de desempenho serve como mecanismo de identificação das deficiências e aptidões dos funcionários, o que permite desenvolver programas de capacitação e treinamento que possam diminuir ou até mesmo suprir tais deficiências.

A função de aumentos salariais e promoção, por sua vez, diz respeito à capacidade que uma avaliação de desempenho tem de dar subsídios à política de promoção e salários. Ou seja, a avaliação pode ser utilizada a fim de gerar informações para discriminação do aumento salarial e promoção. No entanto, tal função pode gerar problemas à organização, visto que, na medida em que a avaliação fica intimamente ligada a essas duas funções, seus outros objetivos são deixados de lado. De acordo com Andreassi, "deve-se ter cuidado para que a avaliação não esteja intimamente atrelada às recompensas salariais, pois isso muitas vezes compromete a viabilidade do sistema". Como será posteriormente 
verificado, tal atrelagem, instituída por lei, é, atualmente, a maior barreira enfrentada pela administração pública no que tange à correta utilização de avaliação de desempenho.

A função de comunicação diz respeito à viabilidade que a avaliação oferece de comunicação entre o chefe e os funcionários, o que pode ser visto, como afirma King (1984), citado por Andreassi (1994), "como meio de se difundirem os objetivos globais da organização entre seus gerentes e funcionários, responsáveis pela consecução desses objetivos”.

Já a função de Planejamento de Recursos Humanos leva em conta a capacidade da avaliação em fornecer subsídios para planejamento estratégico da área de Recursos Humanos. Ou seja, a avaliação de desempenho serve para permitir que a organização estabeleça políticas de desenvolvimento de seus funcionários nos quesitos necessários ao melhor desempenho e utilização dos talentos disponíveis. Em relação aos aspectos legais, na área pública, em geral, a avaliação de desempenho é exigida por lei, a fim de registro do desempenho dos funcionários, como no caso do Brasil, onde serve para cômputo de pontos para promoção salarial.

\section{AVALIAÇÃO DE DESEMPENHO VERSUS ÁREA PÚBLICA}

A administração pública passa hoje por um momento de redefinição de estruturas. O que antes era marcado por ambientes extremamente técnicos, burocráticos e racionais passa a encontrar exigências de renovação. A velha estrutura burocrática não encontra lugar quando nos referimos a organizações cada vez mais enxutas, das quais é exigida mais qualidade na prestação de serviços. Nesse contexto, a área de Recursos Humanos tem papel fundamental, na medida em que se vê responsável por reelaborar sua política de ação com referência aos funcionários, incumbidos de assumir postura diferente frente à nova administração pública.

Espera-se, assim, do funcionário da área pública, um direcionamento para as ações, marcado pelo propósito de realizar. Além disso, espera-se que, ao invés de apenas obedecer, o funcionário assuma responsabilidades, e deixe de ser um sujeito passivo dentro da organização.

Esta área entra, assim, como agente catalisador, capaz de transformar tais funcionários, antes burocratas, em sujeitos ativos e transformadores.

Levando-se em consideração a estabilidade do servidor público vigente na maioria dos países, temos que a gerência de Recursos Humanos deve voltar-se a ações capazes de readequar os funcionários às novas exigências. Assim, direcionam-se as burocráticas funções de pagamento, registro, pensão e aposentadoria para funções de treinamento e desenvolvimento do corpo funcional.

No entanto, como afirma Grillo (1982), “será difícil implantar um programa de recursos humanos em qualquer organização, sem informações adequadas sobre o comportamento das pessoas que nela trabalham. A avaliação de desempenho pode ser o meio de se obterem essas informações”. Nesse contexto, a Avaliação serve como um dos mecanismos para transformações no âmbito funcional das organizações públicas, podendo ser usada no sentido de averiguar deficiências e proporcionar políticas de desenvolvimento profissional. 
No entanto, não tem oferecido o resultado almejado, na medida em que encontra na administração pública dificuldades que restringem sua atuação nessas organizações, como será comprovado nas experiências abaixo citadas.

\section{METODOLOGIA ADOTADA}

\section{Empresas participantes}

Este trabalho baseou-se na análise de experiências realizadas nas prefeituras de São Paulo, Brasil e Sonthofen, Alemanha.

A cidade de São Paulo localiza-se no sudeste do Brasil. Com cerca de 10 milhões de habitantes, é o pólo econômico do país e concentra suas atividades econômicas nas mais diversas áreas; comporta matrizes de inúmeras empresas nacionais e filiais de multinacionais e serve como centro financeiro nacional.

A prefeitura de São Paulo conta hoje com cerca de 105000 servidores públicos estáveis e ativos. É dividida em 17 secretarias responsáveis por áreas diferentes; uma delas, a de Administração, contém o departamento central de Recursos Humanos. No entanto, essa área, que conta com mais de 5.700 funcionários, também funciona descentralizada para as demais secretarias e administrações regionais.

Algumas ações, como concurso, promoção e parte da avaliação de desempenho ainda são centralizadas, mas a maioria das atividades, que por hora são extremamente burocráticas, está descentralizadas. Poucas ações são tomadas atualmente no sentido de desenvolver os profissionais da organização, limitando-se apenas a alguns cursos de treinamento gerencial.

A cidade de Sonthofen localiza-se no sul da Alemanha, no estado da Bavária. A população é de 22.000 habitantes que convivem em uma região montanhosa, abrigo de estação de esqui durante o inverno e de estação de repouso durante o verão.

Além disto, convivem no município muitos militares, cerca de 3000 por ano, divididos em 3 quartéis. A economia da cidade baseia-se no turismo, na renda provinda dos militares e em laticínios, na medida em que a região montanhosa comporta muito gado. A prefeitura tem 300 funcionários, sendo $10 \%$ deles estáveis e $90 \%$ contratados. O funcionamento da prefeitura divide-se em cinco departamentos, cada qual responsável por uma área.

A divisão de Recursos Humanos é composta de três funcionários (diretor e auxiliares) e está subordinada ao departamento de Administração Geral. Os trabalhos relacionados a recursos humanos estão quase totalmente voltados a cumprimento de legislação e de burocracia (pagamento, promoção salarial, aposentadoria...). Raras ações são tomadas para o desenvolvimento profissional, inclusive porque a política do prefeito não se volta para ações nesse sentido.

\section{Coleta de dados}

A coleta de dados foi feita, em ambos os casos, através de experiências práticas vividas por meio de um estágio profissional. O estágio na prefeitura de São Paulo teve duração de um ano, concentrado na área de Recursos Humanos, enquanto que o de Sonthofen teve duração de 6 semanas, e foi concentrado, em 
diversas outras áreas além desta. Os dados foram coletados através de:

- entrevistas com funcionários de diversas áreas dentro e fora da área de Recursos Humanos e com profissionais responsáveis pela avaliação de desempenho das cidades em questão.

- material referente às realidades em questão, como apostilas de aplicação da avaliação de desempenho, formulários recentes e antigos;

- pesquisas bibliográficas locais referentes a estudos já realizados nas prefeituras em questão quanto à gestão de recursos humanos;

- consulta a resultados de avaliações, trabalhos e pesquisas passadas, realizadas dentro e fora da administração municipal.

- estudo de legislação referente a cada município: estudo do estatuto dos servidores públicos do município de São Paulo e da constituição federal. Em Sonthofen, estudo da legislação estadual de servidores públicos.

\section{EXPERIÊNCIAS PRÁTICAS DA AVALIAÇÃO DE DESEMPENHO}

\section{Prefeitura de São Paulo, Brasil}

A prefeitura de São Paulo conta hoje com 105.000 funcionários estáveis e ativos, dos quais cerca de 99.000 são avaliados todos os anos. A Avaliação de Desempenho da PMSP tem caráter obrigatório estabelecido por lei federal e regulamentado pelo estatuto do servidor municipal de São Paulo. De acordo com as normas que regem a avaliação de desempenho no município, ela deve ser anual e sua função está estritamente ligada à promoção por merecimento. Ou seja, os pontos dela provindos são computados para que o funcionário possa ter promoção horizontal (já que tal promoção diz respeito apenas ao crescimento salarial).

Como a avaliação tem caráter restrito à promoção por merecimento, após certo grau de promoção (o chamado grau E), os funcionários deixam de ser avaliados. O mesmo ocorre com aqueles funcionários que ingressaram no serviço público por indicação ou sem concurso (casos que ocorriam no passado).

Os funcionários da PMSP são avaliados por suas chefias por meio de instrumento padronizado enviado pelo órgão central de recursos humanos da prefeitura. A chefia imediata de cada funcionário se responsabiliza por avaliá-lo de acordo com os critérios estabelecidos no formulário unificado de avaliação. Após a avaliação, o funcionário deve ratificar o formulário que será encaminhado para a central de recursos humanos da prefeitura; é, no entanto, responsável apenas por computar os pontos dados a cada funcionário, não dando importância aos comentários da chefia ou às necessidades de treinamento e desenvolvimento de pessoal anotadas nas avaliações.

O instrumento utilizado baseia-se em uma avaliação de desempenho por escala gráfica que consiste em dar notas a itens relacionados ao desempenho do funcionário (como liderança, planejamento, conhecimento do trabalho, pontualidade e etc.). Tal método traz, por um lado, a vantagem de facilitar seu entendimento por quem avalia e por quem é avaliado - fator muito importante quando se trata de organizações cujos funcionários são de diferentes níveis intelectuais. Por outro lado, o instrumento não possibilita flexibilidade, além de desestimular a comunicação entre chefia e funcionário e permitir que a chefia possa ser encarada como juiz e o avaliado como réu. 
O formulário de avaliação é dividido em 7 níveis, de acordo com as atribuições dos diferentes cargos da prefeitura. Tais níveis dizem respeito à formação escolar e profíssional de cada funcionário: Executivo, Assessoria, Chefia, Universitário, Docente, Médio, Operacional e Básico.

\section{AVALIAÇÃO DE DESEMPENHO NA PREFEITURA DE SONTHOFEN, ALEMANHA}

A prefeitura de Sonthofen, Alemanha, conta atualmente com 300 funcionários, dos quais apenas 30 são servidores públicos estáveis. A lei que rege os servidores é estadual; de acordo com ela, apenas os servidores estáveis têm obrigação de se submeter à avaliação de desempenho. Dessa forma, apenas os 30 servidores submetem-se à avaliação que, de acordo com a lei, deve ser aplicada em, no máximo, três anos. No entanto, se o funcionário estiver próximo de ser promovido, pode pedir ao prefeito que o avalie, a fim de ter mais rapidamente ascensão salarial. Já no caso de funcionários provindos de outra cidade onde já foram avaliados, a nova avaliação dar-se-á apenas quando os três anos de sua avaliação anterior forem completados, o que significa que, até então, a avaliação vigente será a efetuada na cidade anterior.

O formulário é dividido em três níveis, de acordo com o nível profissional de quem é avaliado: serviços básicos, médios, altos e superiores. Os formulários são unificados e foram desenvolvidos pela administração pública estadual, de forma que todos os funcionários em cada Estado terão, dentro de seus níveis, a mesma avaliação.

De acordo com a lei, o avaliador deve ser algum dos chefes do funcionário. Mas, como a prefeitura de Sonthofen conta com poucos funcionários, quem avalia é o próprio prefeito, chefia máxima da administração municipal. Dentro da avaliação existem 6 notas que podem diminuir ou aumentar o tempo necessário para que o funcionário seja promovido, considerando-se que tal promoção é horizontal e consiste no aumento de salários. Após atingir o grau máximo de promoção, o funcionário não precisa mais ser avaliado, o que também ocorre aos funcionários com idade superior a 55 anos.

Após a avaliação, o prefeito tem a oportunidade de conversar com os avaliados sobre seu desempenho, antes que a pontuação seja encaminhada ao departamento de Recursos Humanos para cômputo da nota para promoção.

\section{PROBLEMAS QUANTO À AVALIAÇÃO DE DESEMPENHO DAS PREFEITURAS EM QUESTÃO}

\section{Falta de parâmetros de avaliação}

Ambas as avaliações de desempenho não constam atualmente de parâmetros de comparação entre os diversos desempenhos. Ou seja, no caso da PMSP ela depende apenas da percepção da chefia imediata em relação ao servidor e no caso de Sonthofen, depende apenas da visão do prefeito em relação aos funcionários. Assim, as avaliações estimulam opiniões subjetivas da avaliação, que podem conduzir a deficiências como:

a) efeito preconceito pessoal, no qual o avaliador tem preconceito quanto ao avaliado e reflete isso na avaliação ;

b) efeito halo, ocorrido quando o superior gosta muito do avaliado e sua opinião torna-se distorcida, obedecendo a tal sentimento. 
Em ambos os casos, a avaliação perde parte de seu sentido, já que não terá caráter realista em relação ao verdadeiro desempenho dos funcionários.

\section{Desvinculação da avaliação ao gerenciamento de Recursos Humanos}

Em ambos os casos, pode-se verificar que não há relação entre a avaliação de desempenho e o gerenciamento de Recursos Humanos. Os resultados da avaliação são utilizados somente para cômputo de pontuação para promoção de merecimento, no caso de São Paulo, e para determinar o tempo necessário para ascensão de grau, no caso de Sonthofen.

$\mathrm{Na}$ medida em que os resultados são subtilizados, a avaliação perde sua capacidade de fornecer subsídios para desenvolvimentos profissional e conseqüente desenvolvimento organizacional.

\section{Cultura organizacional que subestima a importância da avaliação de desempenho.}

A cultura da PMSP está voltada para uma descrença no instrumento, aliada à falta de perspectivas em relação a ações para desenvolvimento de profissionais da prefeitura.

Como a organização não tem, nos últimos anos, priorizado políticas de desenvolvimento dos funcionários, não se dá credibilidade, em geral, a ações desse tipo. Tratando-se do caso de Sonthofen, encontramos uma realidade muito parecida, que subestima a avaliação na medida em que a utiliza apenas para cumprir o determinado pela lei. Tal fato é constatado, inclusive, pelas ações do prefeito, que não aplica a avaliação com o intuito de reconhecer e transformar falhas na gestão, aplicando o instrumento, se possível, apenas no tempo máximo determinado por lei - a cada três anos. Paralelamente pode-se constatar, nos dois casos, que os resultados se dão apenas no âmbito da promoção, o que leva os funcionários das Prefeituras a não valorizarem o que está sendo avaliado. A avaliação não é, portanto, usada para demonstrar a realidade das prefeituras, mas sim com o intuito de contribuir com a promoção salarial.

\section{Restrição da avaliação à política salarial.}

A restrição da avaliação à política salarial leva a que funções como desenvolvimento e treinamento sejam deixadas de lado. Tal restrição acaba também por incentivar casos em que o avaliador é visto como juiz e o avaliado como réu. Como, em particular, na PMSP existe uma transição grande de cargos, muitas vezes as chefias podem trocar de lugar com seus subordinados, realidade que faz com que os avaliadores tendam a ser neutros com seus avaliados, para que, "no futuro não sejam mal avaliados por quem hoje avaliam", já que a avaliação implica diretamente aumento salarial. No caso de Sonthofen, a avaliação é aplicada somente no tempo determinado por lei, ou quando o funcionário, prestes a subir de grau, pede ao prefeito que o avalie, a fim de adiantar sua ascensão salarial. 


\section{Avaliação restrita a uma pessoa de nível hierárquico superior.}

O fato de a avaliação ser unilateral restringe a visão em relação ao avaliado, o que pode não ter caráter neutro por parte do avaliador. Dessa forma, fatores como preconceitos ou bom relacionamento podem ser aumentados. No caso de Sonthofen em particular, o fato de o prefeito avaliar pode ser prejudicial, na medida em que ele deve assumir muitas funções ao mesmo tempo, o que o impede de analisar de perto o andamento administrativo da prefeitura e, portanto, o desempenho de cada funcionário.

\section{Formulários unificados}

No caso da PMSP, os formulários são divididos em apenas sete categorias funcionais.

Assim, tendem a abranger funções profissionais muito diversas, que, certamente, não poderiam ter avaliação comum. Um exemplo disto é o caso dos pedreiros e ascensoristas avaliados de acordo com o mesmo instrumento, sem que o bom desempenho de um possa estar relacionado ao bom desempenho do outro. Já no caso de Sonthofen, o formulário é unificado para todas as prefeituras do Estado, o que torna o mecanismo mais ineficaz, na medida em que pretende avaliar da mesma forma funcionários de realidades muito diversas.

\section{Formulários falhos}

Os formulários de ambas as prefeituras contêm falhas. Os feitos com base no desempenho por escala gráfica, como é o caso de São Paulo, geram pouca flexibilidade no preenchimento. O avaliador fica restrito a itens com pontuações exatas e comentários fechados, sem poder dar opinião pessoal ou complementar as respostas. Isso pode promover uma avaliação irreal dos fatos. Já o formulário de Sonthofen falha na medida em que contém apenas questões escritas, pouco objetivas, sem direcionamento para respostas comparativas. As perguntas propiciam opiniões subjetivas do desempenho do funcionário, o que pode gerar falhas na avaliação e diminuir, consequentemente, a capacidade de transformação a partir das informações que a avaliação promove.

\section{Alguns funcionários não são avaliados}

Tanto na prefeitura de São Paulo como na de Sonthofen existe o fato de que alguns funcionários deixam de ser avaliados. Isso gera problemas na medida em que não permite que a avaliação sirva como meio de gestão de recursos humanos. Na medida em que nem todas as pessoas são avaliadas, torna-se inviável constituir políticas de desenvolvimento organizacional que atinjam todas as falhas apontadas por uma avaliação. Isso mostra, uma vez mais, a desvinculação da avaliação no que diz respeito a treinamento e desenvolvimento nas prefeituras em questão. 


\section{CONCLUSÃO}

De posse dos dados levantados e dos problemas analisados, pode-se concluir que, em ambas as prefeituras, existem falhas no que diz respeito às funções dadas à avaliação de desempenho. Pode-se perceber que, a partir do método atual, apenas duas funções são utilizadas: - função salarial; - função legislativa.

Para que tal realidade possa ser transformada, maximizando as funções da avaliação nessas cidades, algumas mudanças se fazem necessárias:

1- Dotar a avaliação de parâmetros de comparação

De acordo com Oliveira-Castro (1995) "os sistemas de avaliação devem ser justos e imparciais, baseados em padrões de desempenho atingíveis, objetivos e claros, apoiados na realidade dos cargos ou postos de trabalho. (...)Os fatores de avaliação devem ser claramente definidos e os instrumentos precisam exemplificar ações observáveis, de maneira que possam servir como indicadores de desempenho e referenciais seguros para atribuição de escores". A avaliação deve, portanto, valer-se de indicadores objetivos que possam gerar medidas de comparação entre os diversos desempenhos. Além disto, ela deve ter explicitados os parâmetros a serem analisados para a avaliação, de forma que se possa traçar um paralelo entre o que deve ser observado e a maneira de observar.

\section{2- Vincular os resultados da avaliação à gestão de Recursos Humanos}

Segundo Grillo (1982), a avaliação de desempenho "fornece elementos capazes de informar sobre a correção do instrumento seletivo, bem como situar a s áreas mais carentes de treinamento". (Grillo1982). Nesse contexto, faz-se necessária a percepção de que a preocupação permanente com o desempenho humano e com a maneira de torná-lo mais eficaz na obtenção de resultados é o ponto de atenção máxima para o aumento da produtividade, objetivando o retorno rentável e a participação do sucesso nas organizações. Como conseqüência, as diretrizes para a reformulação e implantação do processo de AD devem ser inspiradas na percepção e no reconhecimento do desempenho humano como fator impulsionador do sucesso da empresa, o que torna a gestão de recursos humanos um fator estratégico. Dessa forma, a avaliação deve ser encarada pela gestão de recursos humanos como instrumento que subsidie ações de melhoria organizacional.

\section{3- Mudança na cultura organizacional}

Como já foi anteriormente constatado, a cultura organizacional de ambas as prefeituras não está voltada para ações que priorizem o desenvolvimento profissional. Assim, a avaliação de desempenho é encarada apenas como cumprimento de legislação. Para que possa funcionar como fator fundamental para o melhor andamento dos serviços, é necessária a instituição de uma cultura que valorize esse tipo de ações. Assim, políticas de sensibilização em relação à importância de uma avaliação devem ser priorizadas. Dessa forma, os avaliados e avaliadores poderão encarar o instrumento de forma a utilizálo para modificar a organização.

4- Desvincular a avaliação à política salarial

A política da avaliação de desempenho das prefeituras em questão deve ser revista de maneira que a avaliação seja ampliada a outras funções. Assim, devem-se ligar a ela ações voltadas a treinamento, desenvolvimento e identificação de habilidades. Além disso, como afirma Lucena (1992), "uma verdadeira revolução se processa no interior das organizações que estão se modernizando, com a 
criação de novos modelos de gestão (...).

Nesse contexto, ações individuais cada vez mais se descaracterizam, dando lugar às ações de grupos, cujos resultados são decorrentes de contribuições compartilhadas". Dessa forma, políticas salariais hierarquizadas e rígidas entram em desacordo com o novo contexto administrativo, o que nos leva à conclusão de que submeter a avaliação à ascensão salarial gera dois erros: um, na medida em que tal ascensão se torna rígida; outro, na medida em que a avaliação é restrita a apenas uma função. Deve-se, portanto, repensar a política da avaliação em um contexto de reestruturação da área de recursos humanos das organizações.

5- Descentralização na formulação do instrumento

De acordo com Grillo (1982), "os resultados obtidos por um processo descentralizados são muito mais reais, pois os métodos utilizados melhor respondem às peculiaridades de cada órgão". Assim, as cidades ou secretarias devem ter autonomia para elaborarem instrumentos que estejam de acordo com as realidades locais. Apenas quem está em contato direto com os avaliados e sabe as necessidades da organização local poderá direcionar a avaliação ao que for necessário para cada ambiente.

6- Avaliação que atinja todos os funcionários

$\mathrm{Na}$ medida e que a cultura e as políticas organizacionais estiverem voltadas ao desenvolvimento, será necessária a ampliação da avaliação a todos os funcionários, já que apenas após ser avaliada toda a realidade da organização, poderão ser elaboradas políticas de desenvolvimento da organização.

7- $\quad$ Novos métodos de avaliação

Para tais organizações, será necessário rever os métodos de avaliação, introduzindo as novas tendências. No que diz respeito a quem avalia, por exemplo, deve ser analisada a possibilidade da implantação de novos sistemas como avaliação $360^{\circ}$, auto-avaliação, e etc. De acordo com Wahrlich (1977), uma saída seria a implantação de comissões de avaliação, que teria, "além do chefe imediato, dois outros membros(...) um especialista em recursos humanos(...) outro que representaria os funcionários mediante eleição por período determinado". Também deve ser analisado, de acordo com a realidade local, o melhor método a ser utilizado, como avaliação por produtividade, escala gráfica, entre outros.

É relevante notar que, apesar de serem realidades vivenciadas em prefeituras muito diversas, pode-se traçar um paralelo em relação aos problemas de ambas as avaliações. Tal fato pode evidenciar um possível atraso que a administração pública sofre em alguns países. Seja por seu imenso tamanho, ou pelas heranças ainda marcantes, a administração pública mundial passa por lenta transição que traz do passado marcas da ineficiência e improdutividade, representadas por ações voltadas ao cumprimento burocrático de legislação.

Para mudar tal realidade, é necessário que a administração pública volte suas atenções para políticas internas, priorizando ações que dizem respeito a seus funcionários. As funções da área de recursos humanos devem ser revistas e reajustadas. Nesse contexto, a avaliação de desempenho pode ter participação essencial, na medida em que identificará as necessidades de mudança. Para que se possam utilizar os dados que a avaliação de desempenho fornece, urge uma readequação da avaliação de desempenho, usando mudanças acima elencadas e maximizando sua ação como agente transformador 
da atual realidade das organizações públicas.

\section{Artigo recebido em 10.04.2001. Aprovado em 16.04.2001}

\section{BIBLIOGRAFIA}

ANDREASSI, T. Avaliação de Desempenho de Profissionais Técnicos: um Estudo de Casos. Dissertação (Mestrado) - Faculdade de Economia, Administração e Contabilidades, Universidade de São Paulo, 1994.

BERGAMINI, C. W. Avaliação de Desempenho Humano na Empresa. São Paulo: Atlas, 1981.

FREITAS, F. E. de. Avaliação de Desempenho Humano: Origem e Desempenho Dentro de Teoria Organizacional. Dissertação (Mestrado) - Escola de Administração de Empresas de São PauloFundação Getúlio Vargas, 1977.

GRILLO, A.N. Avaliação de Desempenho: Experiência Brasileira na Administração Pública. In: Revista de Administração- USP. vol. 17, n. 1, p. 24-35, 1981.

GUIMARÃES, T.A.; NADER, R. M.; RAMAGEM, S. P. Avaliação de Desempenho de Pessoal: uma Metodologia Integrada ao Planejamento e à Avaliação Organizacionais. In: Revista de Administração Pública. vol. 32, n. 6, p. 43-61, 1997.

LIMA, G.B.C.; OLIVEIRA CASTRO, G.A.;VEIGA, M.R.M, Implantação de um Sistema de Avaliação de Desempenho: Métodos e Estratégias. In: Revista de Administração- USP. vol. 31, n.3, p.38-52, 1996.

LUCENA, M. D. da S. Avaliação de Desempenho. São Paulo: Atlas, 1992.

MILANI, I. (1998). Sistema de Avaliação de Desempenho: Revisão de Literatura. Revista de Administração- USP. vol. 23. p. 45-57

WHARLICH, B.; CARVAlHO, M.S.M.V. E MATA, R.A. DA. Painel sobre a Avaliação de Desempenho no Serviço Público Federal. In: Revista de Administração Pública. Vol. 13, n. 1, p. 89$125,1979$. 